\title{
Unexpectedly small semidiurnal tidal wind amplitudes in the mid-latitude mesopause region during September 2002
}

\author{
D. Kürschner ${ }^{1}$ and Ch. Jacobi ${ }^{2}$ \\ ${ }^{1}$ Institute of Geology and Geophysics, University of Leipzig, Talstr. 35, D-04103 Leipzig, Germany \\ ${ }^{2}$ Institute of Meteorology, University of Leipzig, Stephanstr. 3, D-04103 Leipzig, Germany
}

Received: 9 December 2002 - Revised: 10 April 2003 - Accepted: 23 June 2003 - Published: 1 January 2004

\begin{abstract}
The mesopause region monthly mean winds and semidiurnal tidal amplitudes and phases over Central Europe have been measured at Collm Observatory since September 1982. The regular annual cycle of the semidiurnal tidal amplitudes show maximum values during late August and September. In contrast to that, in autumn 2002 no enhancement of the tidal amplitudes was measured, while the autumn tidal phase transition occurred unusually early.
\end{abstract}

Key words. Meteorology and atmospheric dynamics (middle atmosphere dynamics; waves and tides; climatology)

\section{Introduction}

The seasonal behaviour of the semidiurnal tidal (SDT) winds in the mesosphere/lower thermosphere (MLT) region around $80-100 \mathrm{~km}$ has been investigated using ground-based and space-based measurements (Lysenko et al., 1992; Burrage et al., 1995). Also, modelling of the seasonal variation has been performed using modified classical theory (Greisiger, 1975) and numerical models (Hagan et al., 1999; Manson et al., 1999). The authors concordantly report that the SDT wind amplitudes at higher mid-latitudes $\left(50-55^{\circ}\right)$ are small in spring/early summer and late autumn, but larger in winter and above all in late August and September. The phase of the SDT, often defined as the time of maximum eastward wind, generally has different positions in winter and summer, with the latter around $95 \mathrm{~km}$ being about $2 \mathrm{~h}$ earlier than the former (e.g. Greisiger, 1975). The vertical wavelength of the SDT in winter is about $60 \mathrm{~km}$ or smaller, while it is much larger in summer (e.g. Jacobi et al., 1997; Manson et al., 1999). The transition from summer to winter phase generally occurs very regularly during the second half of October.

The mid-latitude mesospheric zonal prevailing winds usually change from summer easterlies to winter westerlies in September, resulting in comparatively low mesospheric winds during this month. On average, the MLT winds at

Correspondence to: Ch. Jacobi (jacobi@uni-leipzig.de) higher mid-latitudes are still eastward and increasing with height (e.g. Portnyagin and Solovjova, 2000), which is typical for summer, but with smaller absolute values, and especially in the mesosphere, rapidly changing to westerly winds, i.e. to winter conditions. At Collm Observatory mean winds and SDT amplitudes and phases near $95 \mathrm{~km}$ have been measured over the last 4 decades. Vertical profiles of those parameters in the height range $85-105 \mathrm{~km}$ are available since September 1982, so that a 21-year data set is available. Here we focus on the unexpected behaviour of the SDT winds in September 2002.

\section{Measurements at Collm}

At Collm Observatory, LF radio wind measurements are carried out on 177,225 , and $270 \mathrm{kHz}$ with differing measuring paths, applying the spaced antenna method and the similarfade method for analysis. The LF measurements use the reflected sky wave at oblique incidence from commercial amplitude modulated radio transmitters, with reflection levels in the MLT between 85 to $105 \mathrm{~km}$ and the centre of the triangle of the three reflection points is located at $52^{\circ} \mathrm{N}$ and $15^{\circ} \mathrm{E}$. The individual measurements on each frequency are combined to half-hourly means, each representing an average of over 30-60 data points, depending on local time, LF propagation, and reflection conditions.

The reference heights are obtained using the amplitude modulation in the frequency range near $1.8 \mathrm{kHz}$ by measuring the travel time differences between corresponding modulation bursts in the sky wave and in the ground wave. Due to the strong absorption of the sky waves in the daytime the measurements are restricted to nighttime and twilight conditions, especially in the summer months.

The obtained half-hour means of the measured zonal and meridional wind components and the reference height are analysed using a multiple regression analysis with heightdependent coefficients. The measurements and data analysis 


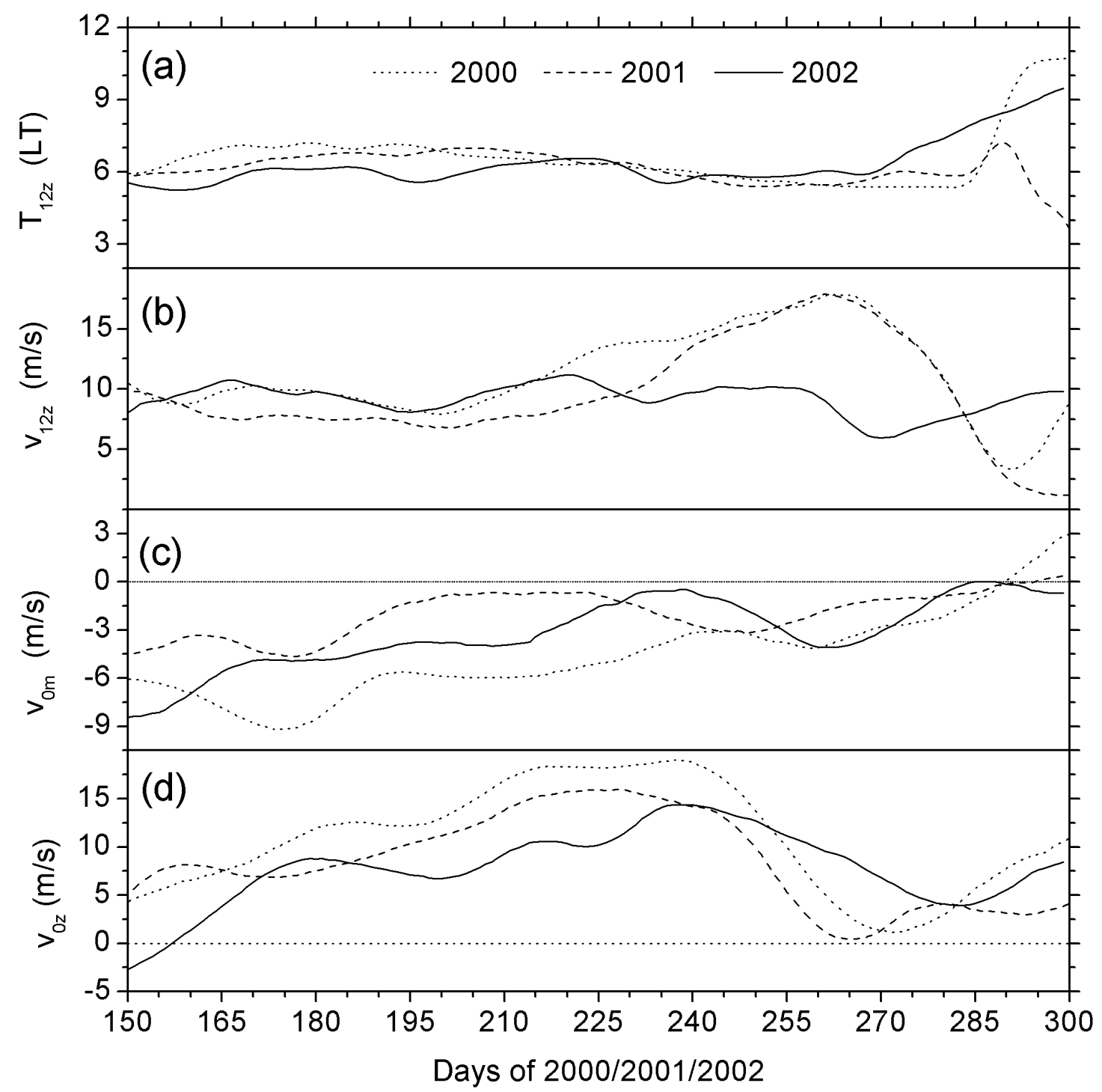

Fig. 1. Time series of (a) zonal SDT phases $\mathrm{T}_{12 z}$, (b) zonal SDT amplitudes $\left(\mathrm{v}_{12 \mathrm{z}}\right)$, (c) meridional prevailing winds ( $\left.\mathrm{v}_{\mathrm{om}}\right)$ and $(\mathbf{d})$ zonal prevailing winds $\left(\mathrm{v}_{\mathrm{Oz}}\right)$ at $93 \mathrm{~km}$ over Collm in summer and autumn 2000, 2001, and 2002.

procedures have been described by Kürschner et al. (1987), Jacobi et al. (1997, 1999), and references therein.

\section{Results for September 2002}

Figure 1 shows time series of the SDT phases $\left(\mathrm{T}_{12}\right)$ and amplitudes $\left(\mathrm{v}_{12}\right)$, together with the meridional and zonal mean wind during summer and autumn 2000, 2001, and 2002. It has been shown, e.g. by Jacobi et al. (1999), that the monthly mean SDT is nearly circularly polarised (see also Fig. 2 below), so that the presentation of the zonal component only is obviously sufficient. The data presented in Fig. 1 has been calculated using multiple regression analyses with quadratically height-dependent coefficients that include the mean winds and the oscillations with periods $12 \mathrm{~h}, 48 \mathrm{~h}, 10$ days and 30 days:

$$
\begin{aligned}
& v(h, t)- \\
& {\left[\sum_{k=0}^{2} h^{k} a_{0 k}+\sum_{j=1}^{4}\left(\sum_{k=0}^{2} b_{j k} h^{k} \sin \omega_{j} t+\sum_{k=0}^{2} c_{j k} h^{k} \cos \omega_{j} t\right)\right]} \\
& \rightarrow \min ,
\end{aligned}
$$

with $v$ being the measured zonal or meridional wind at height $h$, and time $t$ and $\omega$ are the angular frequencies $2 \pi / 12 \mathrm{~h}$, $2 \pi / 48 \mathrm{~h}, 2 \pi / 10 \mathrm{~d}$ and $2 \pi / 30 \mathrm{~d}$ taken into account. From the resulting coefficients $a, b$ and $c$ the vertical profiles of the mean wind and tidal amplitudes and phases can be calculated (see also Jacobi et al., 1997, 1999). We did not include the diurnal tide into the analysis, because the quasi-regular daily data gaps can cause larger errors in some cases. However, as is discussed by Jacobi et al. (1999), discarding the diurnal 


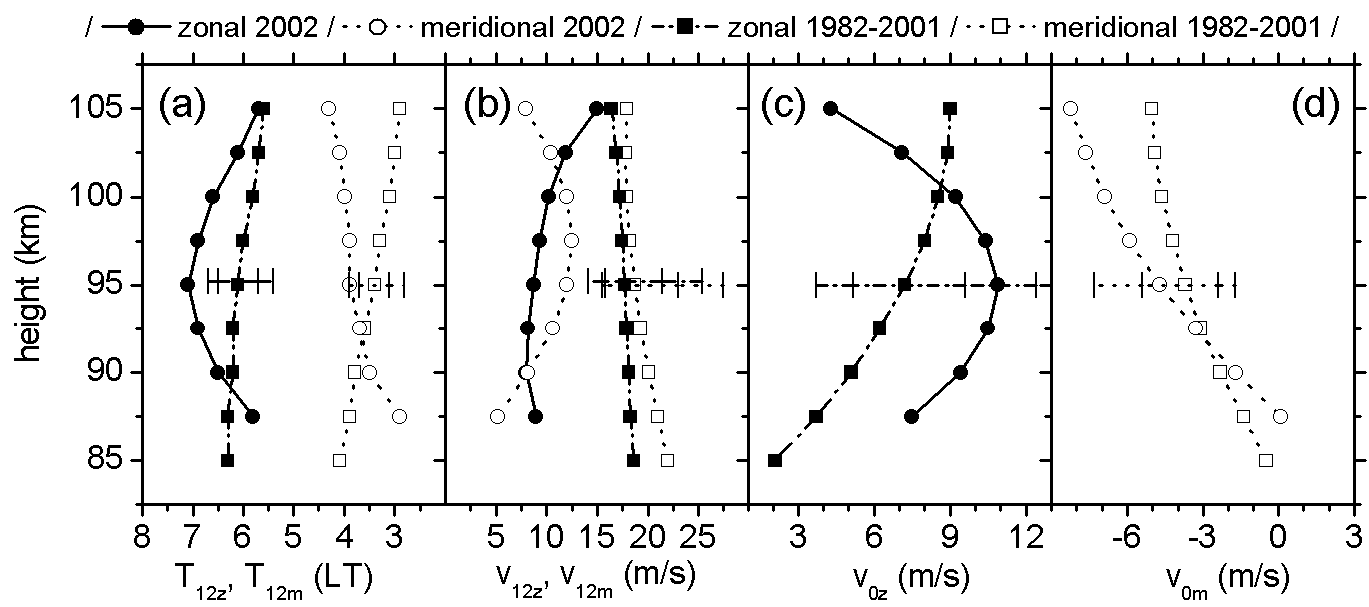

Fig. 2. September 2002 mean profiles of (a) SDT (b) SDT amplitudes (c) zonal prevailing winds and (d) meridional prevailing winds over Collm. The circles show the 2002 values, while squares denote the climatological 20 -year mean values calculated from all September data between 1982 and 2001. The horizontal bars show the maximum/minimum values and the $1-\sigma$ variation during that time interval.

tide does not strongly influence the results for other oscillations and the mean winds. Each analysis was performed on a basis of 25 days with each point weighted equally. The results were attributed to the centre of the 25-day time interval. The long data window was chosen to obtain a more realistic estimate of the prevailing winds without influence of planetary waves and irregular variations. Therefore, it has to be taken into account that this analysis includes a strong smoothing. The results are shown for an altitude of $93 \mathrm{~km}$, which is the height of maximum measuring density during September 2002. Since the tidal amplitudes during September change little with height in the MLT (e.g. Jacobi et al., 1997, see also Fig. 2 below), the exact anchoring height is not decisive for the results.

It can be seen from Fig. 1 that $\mathrm{v}_{12}$ and $\mathrm{T}_{12}$ in early summer 2002 do not strongly differ from those during other years. However, the increase in amplitude that is regularly starting in early August is not visible in the curve for 2002. The tidal amplitudes remain near $10 \mathrm{~m} / \mathrm{s}$ during the whole of August and part of September, while during the second half of September, when a strong maximum is found during other years, even a tendency towards a minimum is visible. The use of the 25-day data window leads to a smoothing effect in the case of variable tidal parameters and consequently, to a reduction of the resulting mean tidal wind amplitudes (vector means), compared with arithmetic mean amplitudes determined without respect to the individual phase values from single daily estimations of 12 -h tides. When analysing estimates after Eq. (1), considering only the SDT and without taking into account the varying measuring height, we obtain a September 2002 mean $v_{12}$ of $14 \pm 5 \mathrm{~m} / \mathrm{s}$. However, monthly means calculated from daily analyses of $\mathrm{v}_{12}$ in 2000 and 2001, similarly as the smoothed values in Fig. 1, are 5 or $6 \mathrm{~m} / \mathrm{s}$ larger, respectively, with similar variability. These analyses also show that $T_{12}$ does not change much from day to day in September 2002. Thus, the smoothing has no qual- itative effect on the comparison of the 2002 tidal amplitudes with those from other years.

The unexpected behaviour of the SDT amplitudes in 2002 is accompanied by a very early change in the SDT zonal phases from their summer value (about 06:00 UT near $93 \mathrm{~km}$ ) to the winter value (about 09:00 LT near $93 \mathrm{~km}$ ). In most years, this change is starting in a very narrow time interval in the second half of October, in the course of which this transition may occur in different ways: either it consists of a sharp phase jump (as in 2000), or of a more moderate progression or also regression of the phase is found (as in 2001). In 2000 and 2001 the phase transition did not start before mid October. In contrast to that, the phase transition in 2002 starts about two weeks earlier.

The meridional mean winds in 2002 do not show any unusual behaviour. The zonal mean winds are different from those during other years in that the decrease in the westerly wind (that in most years also includes easterly winds during a short time interval) is shifted to October 2002, and it is much weaker than usual.

The monthly mean profiles of $\mathrm{T}_{12}$ and $\mathrm{v}_{12}$ and the zonal and meridional prevailing winds are shown in Fig. 2, together with the mean values calculated from all the September data gathered during 1982-2001. The vertical wavelengths, usually calculated from the $\mathrm{T}_{12}$ change with height, are very long or the wave is even evanescent. This is in accordance with other measurements, but is often poorly reproduced in the models (e.g. Manson et al., 1999). To determine whether or not the 2002 profiles are outside the range of previously measured winds, the maximum and minimum values between 1982 and 2001 at $95 \mathrm{~km}$ are also shown, together with the $1-\sigma$ variation during that time interval. It can be seen that both the $\mathrm{v}_{12}$ and $\mathrm{T}_{12}$ values are outside of the range of previously measured values. Comparison with literature results (Lysenko et al., 1992; Manson et al., 1999) also show that none of the $\mathrm{v}_{12}$ presented are as small as those measured at 
Collm in 2002. The prevailing winds fall in the range of previously measured wind values, but there is a weak indication that the zonal prevailing winds in the lower height range considered here is stronger than usual, while this is not the case in the upper height range. This is an indication for an unexpected early transition from summer to winter conditions, i.e. westerlies in the mesosphere and a reversal to easterlies above that layer.

\section{Conclusions}

At Collm, in September 2002, unexpectedly small SDT wind amplitudes have been measured. The September mean amplitudes are smaller than those measured at Collm in any year of observation since 1982. They are also smaller than those presented by other authors (Lysenko et al., 1992; Manson et al., 1999) for different years or different periods. The small $\mathrm{v}_{12}$ have been accompanied by an unexpected early change of $\mathrm{T}_{12}$ from its summer to winter position.

Regarding the mean zonal wind profiles there is some weak indication that the summer mean circulation in the mesosphere has been shifted to mean winter conditions earlier than during other years, so that it is conceivable that the September tides have been modified by an unusual behaviour of the mean circulation. The specific situation in the mesosphere cannot be shown by the MLT measurements. It may, however, be concluded that the seasonal cycle of tidal winds in the MLT is more variable than hitherto assumed.

Acknowledgements. Topical Editor U.-P. Hoppe thanks a referee for his/her work in evaluating this paper.

\section{References}

Burrage, M. D., Wu, D. L., Skinner, W. R., Ortland, D. A., and Hays, P. B.: Latitude and seasonal dependence of the semidiurnal tide observed by the High-Resolution Doppler Imager, J. Geophys. Res., 100, 11313-11 321, 1995.

Greisiger, K. M.: Experimentelle und theoretische Untersuchungen des halbtägigen Gezeitenwindes als Beitrag zur Dynamik und Struktur der Mesosphäre, Z. Meteorol., 25, 205-212, 1975.

Hagan, M. E., Burrage, M. D., Forbes, J. M., Hackney, J., Randel, W. J., and Zhang, X.: GSWM-98: Results for migrating solar tides, J. Geophys. Res., 104, 6813-6828, 1999.

Jacobi, Ch., Schminder, R., and Kürschner, D.: Measurements of mesopause region winds over Central Europe from 1983 through 1995 at Collm, Germany, Contrib. Atmos. Phys., 70, 189-200, 1997.

Jacobi, Ch., Portnyagin, Yu. I., Solovjova, T. V., Hoffmann, P., Singer, W., Fahrutdinova, A. N., Ishmuratov, R. A., Beard, A. G., Mitchell, N. J., Muller, H. G., Schminder, R., Kürschner, D., Manson, A. H., and Meek, C. E.: Climatology of the semidiurnal tide at $52^{\circ} \mathrm{N}-56^{\circ} \mathrm{N}$ from ground-based radar wind measurements 1985-1995, J. Atmos. Solar-Terr. Phys., 61, 975-991, 1999.

Kürschner, D., Schminder, R., Singer, W., and Bremer, J.: Ein neues Verfahren zur Realisierung absoluter Reflexionshöhenmessungen an Raumwellen amplitudenmodulierter Rundfunksender bei Schrägeinfall im Langwellenbereich als Hilfsmittel zur Ableitung von Windprofilen in der oberen Mesopausenregion, Z. Meteorol., 37, 322-332, 1987.

Lysenko, I. A., Makarov, N. A., Portnyagin, Yu. I., Kashcheyev, B. L., Lizogub, V. V., Sidorov, V. V., and Fahrutdinova, A. N.: Seasonal and latitudinal variations of the lower thermosphere tidal winds from meteor radar measurements in the U.S.S.R., J. Atmos. Terr. Phys., 54, 915-926, 1992.

Manson, A., Meek, C., Hagan, M., Hall, C., Hocking, W., MacDougall, J., Franke, S., Riggin, D., Fritts, D., Vincent, R., and Burrage, M.: Seasonal variations of the semi-diurnal and diurnal tides in the MLT: multi-year MF radar observations from 2 to $70^{\circ} \mathrm{N}$, and the GSWM tidal model, J. Atmos. Solar-Terr. Phys., 61, 809-828, 1999.

Portnyagin, Yu. I. and Solovjova, T. V.: Global empirical wind model for the upper mesosphere/lower thermosphere. I. Prevailing wind, Ann. Geophysicae, 18, 300-315, 2000. 